\title{
SANTOS REGO, Miguel; LORENZO MOLEDO, Mar (Eds.) (2012). Estudios de pedagogía intercultural. Campinas, Barcelona: Octaedro (188 páginas)
}

Sob a responsabilidade editorial de dois conhecidos investigadores e professores da Faculdade de Ciências da Educação da Universidade de Santiago de Compostela, a presente obra investe competentemente o campo da pedagogia intercultural ao longo de seis capítulos, reapresentando estudos já realizados e adiantando novos conteúdos e novos desenvolvimentos, visando em conjunto o reforço e a consolidação dessa importante área dos estudos pedagógicos, precisamente numa altura em que a sua necessidade é por todos reconhecida tendo em conta a diversificação galopante dos cenários sociais atuais e os desafios daí resultantes em termos de educação com critérios de igualdade e justiça.

Dado o interesse do livro para a fundamentação de iniciativas pedagógicas com públicos escolares multiculturais, e atendendo a que é potencialmente inspirador de novas investigações nesse campo, convém apresentar, com algum pormenor, os capítulos que dão corpo e espessura à densa narrativa de estudos e conceptualizações da obra em análise.

O primeiro capítulo, intitulado: Teoría de la educación, ciudadanía y pedagogía intercultural en la sociedad del aprendizaje, da autoria de Santos Rego \& Lorenzo Moledo, passa em revista e discute perspetivas normativas sobre a educação intercultural enquanto "recurso estratégico de uma educação para a democracia" (p. 47), nomeadamente no contexto de sociedades de aprendizagem que sofrem os efeitos da globalização e da imigração sem retorno.

As perspetivas em discussão, abrangendo a própria reconstrução dos meios e dos fins da teoria da educação (pp. 38-39), assentam na constatação de que é imperioso ter em conta, nas nossas sociedades e nas instituições educativas, a nova fenomenologia das relações humanas, doravante pautadas pela diversidade de culturas, religiões, costumes, ideologias e etnias da mais diversa natureza e origem (p. 20). Esta diversidade étnico-cultural emergente, somada à diferenciação e à segmentação no seio da cultura maioritária, coloca duas exigências incontornáveis nas democracias multiculturais atuais: por um 
lado, a consideração e o respeito pela diversidade cultural que "não oprime ou anula a autonomia do sujeito" e, por outro, a ação que visa, para todos e todas, uma verdadeira igualdade de oportunidades, seja na escola, seja fora dela. A educação intercultural, uma vez liberta das conceções monolíticas de cultura, tem por ambição, não propriamente o "conhecimento dos elementos culturais de cada tradição" (p. 32), mas a aceitação e o reconhecimento do "indivíduo concreto que vive numa cultura concreta e exige ser reconhecido como tal" ( $p$. 33). Ou seja, e talvez de forma mais ampla, "o eixo de interesse da educação intercultural deve centrar-se em promover as condições educativas desejáveis para que pessoas de diversas culturas se encontrem, convivam e estabeleçam entre elas laços de verdadeira comunicação" (p. 36). Assim, o objeto da educação intercultural não é mais a diferença cultural, mas o indivíduo com uma configuração identitária especial em termos étnicos e culturais. A esta luz, a educação intercultural, e a teoria que a deve suportar, ou seja, a pedagogia intercultural, precisa de evitar o excessivo cognitivismo das perspetivas mais comuns, assentes na compreensão e no conhecimento das culturas, ignorando que o essencial se joga nos registos da comunicação e dos afetos entre alteridades culturais diferentes (p. 38). Da mesma forma, há que ir além da escola e dos ambientes formais de aprendizagem, revalorizando as atividades interculturais de tipo extraescolar ou informal no seio das organizações da sociedade civil. O que importa, verdadeiramente, é promover as competências interculturais que são necessárias à relação com os diferentes culturais, entendendo essas competências não como "destrezas puras e duras", mas como capacidades de "participação ativa e crítica em cenários sociais caraterizados pela diversidade cultural e a pluralidade identitária dos indivíduos", e abarcando, no mesmo arco, tanto o cognitivo como o afetivo e o comunicativo (p. 43).

O segundo capítulo, de Santos Rego, e subordinado ao título Sostenibilidad y educación intercultural: el cambio de perspectiva, não se limitando a uma "conotação exclusivamente ecológica e ambiental" (p. 56) do desenvolvimento sustentável, articula este com a educação intercultural no sentido de defender que a "educação intercultural é um adequado recurso estratégico em prol da sustentabilidade, da equidade, da paz e da coesão social" (p. 57), especialmente nas áreas de maior confluência de diversidade étnico-cultural, resultante dos fluxos migratórios propulsados pelo diverso e complexo fenómeno da globalização (p. 60). 
Ao longo do capítulo várias referências se convocam para defender essa tese, nomeadamente a que reporta o pensamento elaborado na cimeira das Nações Unidas de Joanesburgo em 2002. Segundo Santos Rego, foi nessa cimeira "onde abertamente se reconheceu que é na educação que reside o potencial realizador de uma visão da sustentabilidade com possibilidades de articular bem-estar, diversidade cultural e recursos existentes no planeta" (p. 67). A sustentabilidade, como não se cansa de reiterar, não é uma abstração à margem das pessoas e das suas vidas. $O$ centro das preocupações relacionadas com o desenvolvimento sustentável é o ser humano situado e contextualizado, com as suas idiossincrasias, a sua cultura, língua, costumes, tradições e religiões. Daí a importância da "convergência entre educação intercultural e sustentabilidade" (p. 78), no meio escolar e fora dele, por forma a salvaguardar a convivência, a coesão e a paz social.

Assim, e recuperando duas ideias finais do capítulo em análise, importa sublinhar, por um lado, a união indissolúvel entre sustentabilidade e interculturalidade e, por outro, a conveniência de articular, na intervenção sociocomunitária e no currículo escolar, projetos de educação intercultural com projetos de sustentabilidade.

O terceiro capítulo, de Santos Rego, Lorenzo Moledo e Priegue Caamaño (Aprendizaje cooperativo, formación del profesorado y buenas prácticas en pedagogía intercultura), dentro da economia narrativa da obra, assume como objetivo "analisar de que modo é que a introdução da aprendizagem cooperativa na prática pedagógica dos professores contribui para o seu desenvolvimento pessoal e profissional" (p. 92) em contextos letivos étnica e culturalmente diversos, tendo por base uma experiência pedagógica de formação, aplicação e avaliação da técnica Jigsaw de Aronson num total de seis professores e de 123 alunos de escolas galegas de Educación Secundaria Obligatoria (alunos entre os 12 e os 16 anos). A experiência mostra que a técnica não é apenas pertinente na formação contínua dos professores que têm de lidar com públicos escolares muito diversos do ponto de vista étnicocultural (p. 107). Se é verdade que a aplicação dessa técnica em contexto de sala de aula favorece uma intervenção pedagógica de caráter intercultural ( $p$. 108) e reforça a autoconfiança dos professores envolvidos na experiência, também é certo que é benéfica para os alunos: "são os próprios alunos que comandam o seu processo de aprendizagem"; "aumenta de forma notória a 
motivação de aprendizagem nos alunos"; e "supõe um maior grau de ativação discente no seu processo de aprendizagem" (p. 107). O que o capítulo quer demonstrar, em termos pedagógicos, é que as técnicas de aprendizagem cooperativa (como a técnica do Puzzle de Aronson) não são de subestimar em termos de educação intercultural na sala de aula e que são bastante interessantes para a formação contínua dos professores. As boas práticas em pedagogia intercultural, segundo o capítulo analisado, passam necessariamente pela implementação dessas técnicas com alunos de origens culturais e linguísticas diferentes que acederam, justamente, às escolas.

O objetivo fundamental do quarto capítulo (Familias inmigrantes $y$ desarrollo educativo intercultural desde la escuela) de Santos Rego e Lorenzo Moledo, depois de lançar um olhar crítico à participação das famílias imigrantes no sistema escolar do país vizinho, consiste em "defender que o desenvolvimento educativo intercultural das famílias em geral, e das famílias imigrantes em particular, deve associar-se, antes de mais, ao princípio de participação na esfera pública da sociedade civil e, mais concretamente, na escola" (p. 116).

Como a participação das famílias imigrantes nos centros educativos escolares é notoriamente baixa (p. 121), e porque essa participação se revela essencial à integração social, quer dos adultos, quer das crianças dessas famílias, os autores informam, neste capítulo, que desenharam, implementaram e avaliaram "um programa socioeducativo em contexto escolar visando a melhoria da relação escola-família" (p. 122) da população imigrante que hoje dá colorido ao sistema escolar espanhol. O objetivo principal do programa passava por melhorar o conhecimento que essas famílias têm da cultura e da sociedade do país de acolhimento, assim como do seu sistema educativo, com a intenção, pragmática, de aumentar os seus níveis de participação nas escolas frequentadas pelos seus filhos e filhas (p. 125). O programa, intitulado "Programa Socioeducativo para Famílias Imigrantes", desenvolveu-se em cinco centros escolares e abrangeu cerca de 120 pessoas, sendo 65 de um grupo experimental e 54 do grupo de controlo. Além disso, contou com a colaboração da sociedade civil, nomeadamente associações que trabalham com e para os imigrantes.

À luz da investigação realizada, admitem os autores que "um programa com essas caraterísticas pode servir como instrumento optimizador das 
práticas que procuram melhorar a relação família-escola já que favorece a implicação de pais e mães na educação escolar dos seus filhos e filhas" ( $p$. 131) e que é "primordial conseguir a implicação e a colaboração de outros agentes da comunidade educativa e da sociedade civil em geral" (p. 133), uma vez que a relação das famílias e das crianças imigrantes com as escolas e as comunidades em geral se vê influenciada ou condicionada pela vida local.

O quinto capítulo, de Santos Rego, Lorenzo Moledo e Priegue Caamaño (La infancia de la inmigración: qué relevancia se otorga a la educación?), fruto de um trabalho anterior dos autores, estuda a importância que as famílias imigrantes em Espanha atribuem à educação escolar dos seus filhos e procura averiguar, através de uma investigação quase-experimental junto de imigrantes africanos e latino-americanos, se a origem étnico-cultural é uma variável com peso significativo nos resultados desse estudo (p. 140).

Os dados fornecidos pela investigação, comprovando "a importância que as famílias imigrantes outorgam à educação dos seus descendentes" ( $p$. 158), mostram contudo que a atribuição desse valor não se correlaciona com a origem ou procedência étnico-cultural dos imigrantes. O que se torna manifesto, isso sim, é que essa variável pesa nas expectativas que docentes e opinião pública possuem sobre as relações de certos grupos de imigrantes com a instituição escolar (p. 158) e, assim, sobre a sua eventual participação nos assuntos escolares dos filhos. Ora, se é verdade que a escola é um importante "vetor de integração social e cultural dos filhos do imigrantes e das suas famílias" (p. 140), como sublinham mais uma vez os editores do livro, torna-se necessário levar em linha de conta o peso da origem étnico-cultural dos imigrantes nas expectativas dos professores e público em geral, quanto mais não seja para desfazer falsas representações e assim facilitar a implicação das famílias imigrantes nos percursos escolares dos filhos - a qual se revela altamente significativa em termos de aproveitamento académico.

O propósito do sexto e último capítulo, indexado a Santos Rego, Lorenzo Moledo, Gódas Otero e Crespo Comesaña (Inmigración y segregación en un contexto escolar. La pedagogia intercultural en su encrucijada), partindo da constatação de que os imigrantes se tornam cada vez mais residentes permanentes no país vizinho, procura analisar, para fins político-educativos, "se se está a produzir uma distribuição equilibrada dos alunos de origem imigrante pelos centros educativos" (p. 163), nomeadamente da rede de 
instituições escolares públicas da Comunidade Autónoma da Galiza. Os dados empíricos, diferentemente do que acontece em outras Comunidades do Estado espanhol, não confirmam índices significativos de segregação escolar dos alunos originários da imigração: "É possível afirmar, dizem os autores deste capítulo, que a segregação entre os centros públicos da Comunidade, na altura de escolarizar os alunos imigrantes, ou é mínima, ou brilha pela ausência" (p. 181). Uma das razões pode ter que ver com a menor "pressão" de imigrantes sobre o sistema educativo da Galiza, porém, outras "poderiam dever-se ao facto de que boa parte da população estrangeira está escolarizada em Centros de pequenas e médias populações (tão abundantes na Galiza), cuja oferta de escolarização é quase totalmente pública" (p. 181). Seja como for, entendem os autores que é preciso mobilizar recursos e dar formação adequada aos professores para combater quaisquer sinais de segregação escolar, dado pôr em causa uma educação pluralista e colocar, a prazo, sérios problemas de coesão e justiça social.

A obra que se desenvolve ao longo destes capítulos não é o "último grito" em pedagogia intercultural e nem sequer tem a pretensão de a delimitar de uma vez por todas. Os seus autores estão conscientes que essa pedagogia é um projeto em construção e que dificilmente teremos nos próximos anos um cânone teórico-metodológico definitivo, pronto a ser usado em todo o lado, seja nas escolas, seja na intervenção sociocomunitária. Ainda assim, e não obstante conceder, talvez em excesso, demasiado protagonismo às instituições escolares no processo de integração social e cultural dos imigrantes e seus descendentes nas sociedades para onde convergem os novos fluxos migratórios, estamos convictos que a obra abre horizontes à implementação da pedagogia intercultural em cenários sociais multiculturais e que é inspiradora de investigações necessariamente obrigatórias a quem envereda por esse caminho, nomeadamente quando está em causa a equação "imigração-educação-inclusão". De realçar, pela sua novidade e pelo seu sentido de oportunidade, a revalorização do contributo educativo da sociedade civil e a sua importante articulação com as iniciativas pedagógicas das escolas quando se trata de facilitar o processo de integração social e cultural das famílias imigrantes nas sociedades onde se instalam como residentes permanentes. Este é um ponto forte dos vários estudos reunidos na obra editada por Santos Rego e Lorenzo Moledo e é provável que se venha a tornar, 
nos próximos anos, uma referência obrigatória no campo das conceptualizações e das operacionalizações da pedagogia com pretensões interculturais.

Manuel Barbosa

Instituto de Educação, Universidade do Minho 